\title{
EVALUASI KINERJA PENYEDIAAN AIR BAKU EMBUNG SEI GESEK DENGAN PENDEKATAN BALANCED SCORECARD
}

\author{
Wisdawaty Situmorang, Nadjadji Anwar, \& Theresia Sri Sidharti \\ Departemen Teknik Sipil, FTSLK, Institut Teknologi Sepuluh Nopember \\ E-mail: wisdawaty.situmorang@gmail.com \\ Telp: +6282 272252757;
}

\begin{abstract}
ABSTRAK
Infrastruktur sumber daya air yang sangat diandalkan untuk memenuhi kebutuhan air baku di Kabupaten Bintan adalah embung, salah satunya adalah Embung Sei Gesek. Debit air Embung Sei Gesek mengalami penurunan setiap tahunnya. Selain itu, banyaknya tanaman gulma pada permukaan storage, dan penanganan sedimentasi yang belum pernah dilaksanakan dikhawatirkan dapat mempengaruhi kinerja penyediaan air baku. Hal itulah yang menyebabkan evaluasi terhadap kinerja penyediaan air baku Embung Sei Gesek perlu dilakukan. Pada penelitian ini, evaluasi kinerja dilakukan dengan pendekatan balanced scorecard yang menggunakan lima perspektif (Bidang Kinerja Kritis) dalam mengukur kinerja suatu organisasi yaitu misi, pelanggan, pembelajaran dan pengembangan, Proses Bisnis Internal, dan Keuangan. Pemberian nilai untuk kuesioner mengacu pada panduan yang disusun oleh penulis dengan menggunakan rating scale 1 s.d. 5. Dari hasil penelitian diperoleh nilai kinerja untuk tiap perspektif yaitu misi sebesar 4,34; pelanggan sebesar 4,28; pembelajaran dan pengembangan sebesar 4,16; proses bisnis internal sebesar 4,24, dan keuangan sebesar 4,25. Dengan demikian, kinerja penyediaan air baku Embung Sei Gesek dinilai baik.
\end{abstract}

Kata kunci: evaluasi kinerja, embung, balanced scorecard, penyediaan air baku

\begin{abstract}
Retention basin is one of the most reliable water resources infrastructures to supply raw water needs in Bintan Regency, one of them is Sei Gesek Retention Basin. Water debit of Sei Gesek Retention Basindecrease every year. In addition, blooming algae on storage surface, and handling of sedimentationthat has never been implemented is feared to affect the performance of raw water supply. Therefore it is necessary to evaluate the raw water supply ofSei Gesek Retention Basin. In this study, performance evaluation is carried out using a balanced scorecard that uses five perspectives (Critical Performance Area) in measuring the organization performance, namely mission, customers, learning and development, internal business processes, and finance. Grading for the questionnaire refers to assessment guide prepared by the author with using a rating scale 1 to 5 . From the study results obtained the performance value for each perspectives they are mission is 4.34; customer is 4.28; learning and development is 4.16; internal business process is 4.24, and financial is 4.25 . Therefore, performance of raw water supply for Sei Gesek Retention Basin is considered good.
\end{abstract}

Keywords: performance evaluation, retension basin, the balanced scorecard, raw water supply 


\section{PENDAHULUAN}

Kabupaten Bintan Provinsi Kepulauan Riau telah berkembang menjadi kawasan perdagangan dan pelabuhan bebas sebagai dampak dari Free Trade Zone. Perkembangan kawasan tersebut mendorong tingkat pertumbuhan penduduk yang cukup pesat, yaitu sekitar $10 \%$ kenaikan pertumbuhan penduduk pertahunnya. Tingkat perkembangan penduduk yang pesat tersebut tentu saja mendorong peningkatan kebutuhan akan pemenuhan air untuk domestik, municipal dan industri. Salah satu langkah yang telah diambil oleh Pemerintah Kabupaten Bintan Provinsi Kepulauan Riau untuk mengatasi permasalahan tersebut adalah dengan penyediaan air baku berupa kolam tampungan yaitu embung (SID Penyediaan Air Baku Sungai Gesek, 2015).

Tingkat keberhasilan pembangunan suatu embung dapat dinilai dengan cara menganalisis kinerjanya, dengan cara melakukan sistem pendekatan yang mengacu pada 3 aspek. Ketiga aspek tersebut yaitu aspek fisik, aspek pemanfaatan, dan aspek operasi dan pemeliharaan (O\&P). Suatu embung dikatakan baik atau berhasil apabila ditinjau dari aspek fisik, embung tersebut tidak terdapat kerusakan yang cukup berarti pada komponenkomponen fisik selama masa layanannya. Apabila dilihat dari aspek pemanfaatannya maka embung dikatakan berhasil, jika embung dapat memberikan ketercukupan air untuk memenuhi kebutuhan hidup masyarakat sekitar. Jika dilihat dari aspek operasi dan pemeliharaan maka embung dinilai dari lancar atau tidaknya kegiatan institusi atau kelompok pengelolaan dan pemeliharaan sarana embung oleh masyarakat (Wilhelmus, 2013).

Embung menjadi salah satu infrastruktur air yang sangat diandalkan untuk memenuhi kebutuhan air baku di Kabupaten Bintan (SID Penyediaan Air Baku Sungai Gesek, 2015), yang salah satunya adalah Embung Sei Gesek. Embung Sei Gesek dikelola oleh Satuan Kerja Operasi dan Pemeliharaan Balai Wilayah Sungai Sumatera IV. Kegiatan operasi dan pemeliharaan jaringan distribusi air dilaksanakan oleh PDAM Tirta Bintan yang sekaligus merupakan perusahaan pengelola air minum daerah di Kabupaten Bintan. Kesiapan dan keandalan fasilitas dan peralatan-peralatan yang dimiliki perusahaan harus dipelihara agar tidak mengganggu proses produksi. Hal ini tentu harus didukung oleh sistem pemeliharaan yang efektif dan efisien. Operasi dan pemeliharaan harus dikoordinasikan. Pemeliharaan hanya merupakan pendukung dari operasi, akan tetapi jika pemeliharaan tidak baik maka pengoperasian akan gagal atau kurang berhasil. Suatu kegiatan pemeliharaan yang dilaksanakan secara terencana dan periodik dalam bentuk penjadwalan (time schedule), bertujuan untuk mengurangi kemungkinan kerusakan, gangguan dan menjaga fasilitas dalam kondisi standar (Muhtadi, 2009).

Adanya kesenjangan antara kondisi kinerja penyediaan air baku saat ini dengan kondisi ideal/kondisi yang diharapkan dari kinerja penyediaan air baku Embung Sei Gesek menjadi dasar dilakukannya penelitian ini. Adapun kesenjangan tersebut ditunjukkan pada tabel 1.

Permasalahan-permasalahan yang disebutkan pada tabel 1 di atas dikhawatirkan dapat mempengaruhi kinerja penyediaan air baku Embung Sei Gesek. Hal itu menjadi alasan perlunya evaluasi terhadap kinerja penyediaan air baku Embung Sei Gesek untuk memperoleh data dan hasil yang akurat mengenai kinerja eksisting embung. Menurut Antono (2013), banyak metode untuk mengukur kinerja suatu organisasi, antara lain: metode Malcolm Baldridge National Wuality Award (MBNQA), Balanced scorecard (BSC), Six Sigma, dan lain-lain. BSC merupakan salah satu metode yang dalam dekade terakhir ini sangat 


\section{Wisdawaty Situmorang \\ Nadjadji Anwar \\ Theresia Sri Sidharti}

popular digunakan dalam sektor bisnis dan usaha (Isnugroho, 2013). Hasil evaluasi kinerja penyediaan air baku Embung Sei Gesek diharapkan dapat dijadikan sebagai bahan pertimbangan bagi Balai Wilayah Sungai Sumatera IV dalam melaksanakan pengelolaan embung yang lebih baik. Hal ini bertujuan supaya embung dapat berfungsi sesuai dengan rencana dan memberikan kinerja yang maksimal serta menambah wawasan peneliti terkait evaluasi kinerja suatu aset infrastruktur khususnya bidang sumber daya air dengan pendekatan balanced scorecard. Selain itu, diharapkan penelitian ini juga dapat dijadikan sebagai referensi untuk penelitian sejenis berikutnya.

Tabel 1.

Gap Analysis

\begin{tabular}{|c|c|}
\hline Kondisi eksisting & Kondisi ideal \\
\hline $\begin{array}{l}\text { Menurunnya jumlah debit air sementara } \\
\text { jumlah penduduk mengalami kenaikan } \\
\text { setiap tahunnya (Debit outflow rencana }\end{array}$ & $\begin{array}{l}\text { Terpenuhinya kebutuhan air bersih bagi } \\
\text { masyarakat di Kabupaten Bintan. }\end{array}$ \\
\hline
\end{tabular}

Sekitar $40 \%$ gulma/tanaman air terkumpul di sekitar kolam tampungan (storage).

Maksimal gulma/tanaman air yang berada pada kolam tampungan adalah $5 \%$.

Kegiatan pemeliharaan rutin yang Terlaksananya kegiatan pemeliharaan dilakukan selama ini hanya pemeliharaan rutin tidak hanya pada lingkungan terhadap lingkungan sekitar embung. sekitar akan tetapi juga pada tubuh embung.

Penanganan untuk mengurangi sedimentasi pada kolam tampungan (storage) belum pernah dilakukan. Hal Penanganan sedimentasi setidaknya tersebut menyebabkan timbunan sedimen semakin tinggi tiap tahunnya.

Terbatasnya dana yang tersedia untuk Setidaknya tersedia alokasi dana untuk kegiatan pemeliharaan. kegiatan pemeliharaan rutin dan berkala.

Jumlah SDM pengelola OP yang belum Tersedianya SDM pengelola OP sesuai memadai. dengan analisis jabatan dan analisis beban kerja.

Sumber: data diolah penulis

Penelitian sejenis telah dilakukan oleh Eny Setyaningrum pada tahun 2014 dengan judul "Evaluasi Kinerja Embung Air Baku di Pulau Madura" dengan menggunakan metode Structural Equation Model. Pada penelitian tersebut, kinerja organisasi pengelola embung hanya diukur dari kondisi fisik embung, lingkungan, pengelolaan, dan kelembagaan. Penelitian sejenis juga sudah pernah dilakukan oleh Yulianthi Dethan dkk. dengan judul jurnal "Evaluasi Kinerja Embung Oeltua" dengan metode skala likert dimana indikator kinerja yang digunakan antara lain ketersediaan air, fisik, pemanfaatan, O\&P, dan manajemen organisasi. Kedua penelitian sejenis terdahulu tersebut belum menggunakan aspek keuangan sebagai indikator kinerja embung. 
Pada penelitian ini penulismemilih untuk menggunakan metode balanced scorecard karena indikator kinerja yang digunakan dengan metode ini dianggap lebih lengkap karena telah mencakup aspek keuangan dan non keuangan (misi, pembelajaran dan pengembangan, proses bisnis internal, dan pelanggan). Kinerja organisasi pengelola embung dapat diukur secara berimbang dengan menggunakan aspek keuangan dan non keuangan sebagai indikator kinerja. Hal itu meyebabkan metode balanced scorecard dianggap paling tepat untuk menyelesaikan permasalahan pada penelitian ini. Sebagai informasi, pengukuran kinerja organisasi secara keseluruhan telah dilakukan oleh BWS Sumatera IV setiap tahunnya melalui Laporan Akuntabilitas Kinerja Instansi Pemerintah (LAKIP), namun kinerja yang diukur terbatas pada kinerja keuangan saja.

\section{METODE}

Penelitian ini menggunakan analisa deskriptif kualitatif yang mendeskripsikan variabelvariabel yang berkenaan dengan masalah dan unit yang diteliti. Variabel dan sub variabel yang berpengaruh terhadap kinerja penyediaan air baku embung diperoleh berdasarkan kajian dari beberapa literatur dan wawancara dengan beberapa narasumber yang berkompeten di bidang embung. Pada penelitian ini evaluasi kinerja penyediaan air baku Embung Sei Gesek dilakukan dengan pendekatan balanced scorecard yang menggunakan lima perspektif dalam mengukur kinerja suatu organisasi (RBO Ditjen SDA, 2015), seperti yang ditampilkan pada Bagan 1.

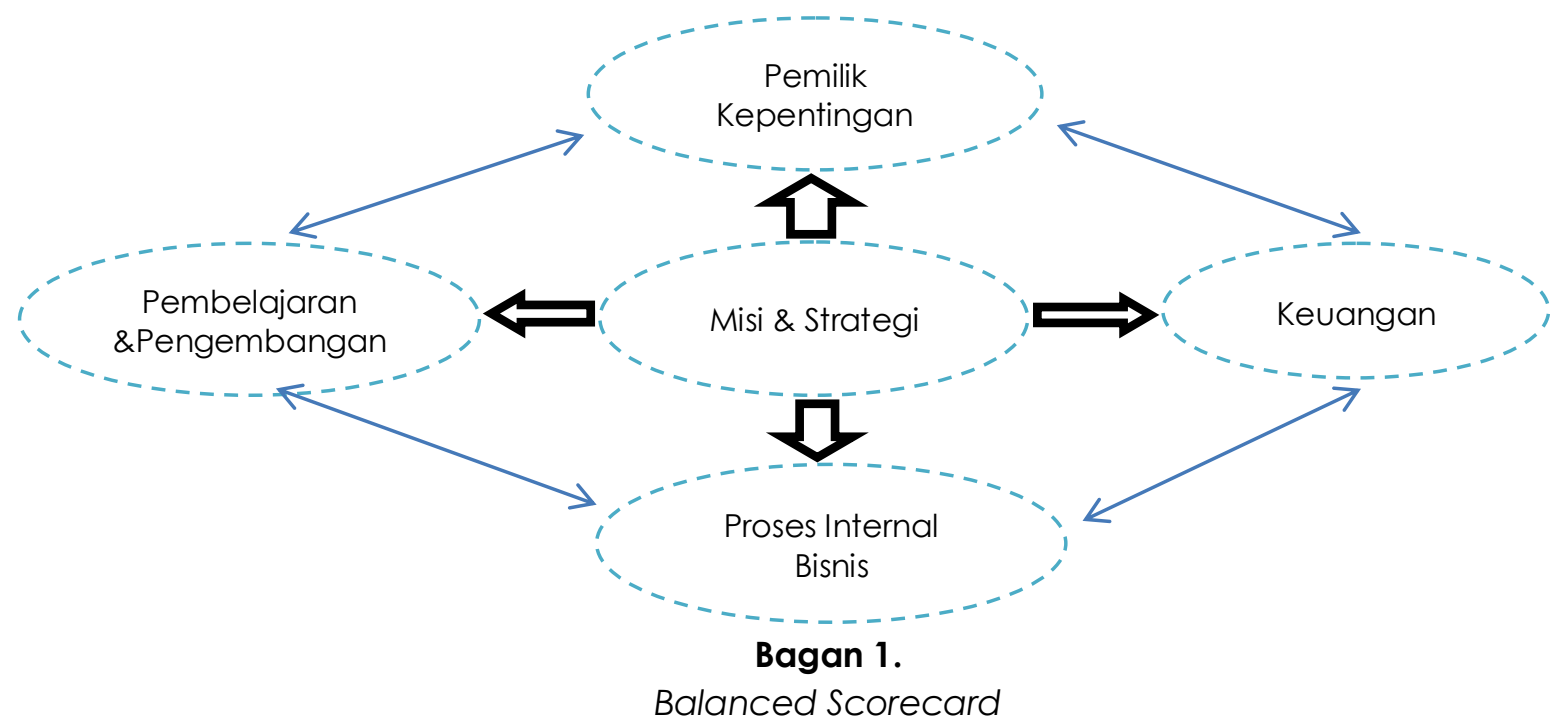

Sumber: Balanced Scorecard dengan Six Sigma (Gaspersz, 2006)

Analisa penilaian kinerja dilakukan terhadap persepsi responden atas kelima perspektif yang tertuang dalam kuesioner. Pemberian nilai untuk kuesioner mengacu pada panduan penilaian yang disusun oleh penulis dengan menggunakan rating scale 1 s.d. 5 seperti yang ditunjukkan pada tabel 2. Jenis kuesioner yang digunakan adalah kuesioner skala likert.

Kemudian nilai kinerja dihitung dengan menggunakan rumus Widiyarto (2017) sebagai berikut:

berikut:

Nilai Kinerja $=\frac{\text { Total Nilai } B S C}{\text { Total Nilai Max }} \times$ Nilai Max

Pada penelitian ini, variabel dan parameter yang dianggap berpengaruh terhadap kinerja penyediaan air baku Embung Sei Gesek ditunjukkan pada tabel 3. 
Tabel 2.

Skala Penilaian Kinerja

\begin{tabular}{lcc}
\hline \multicolumn{1}{c}{ Skala Pengukuran } & Skor & Rerata \\
\hline Sangat Baik & 5 & $4,51-5,00$ \\
Baik & 4 & $3,51-4,50$ \\
Cukup Baik & 3 & $2,51-3,50$ \\
Tidak Baik & 2 & $1,51-2,50$ \\
Sangat Tidak Baik & 1 & $1,00-1,50$ \\
\hline
\end{tabular}

Sumber: Metode Penelitian (Sugiyono, 2010)

Tabel 3.

Variabel dan Parameter Penelitian

\begin{tabular}{|c|c|c|c|}
\hline Kode & Variabel & Sub-variabel & Tujuan \\
\hline A & $\begin{array}{l}\text { Misi Bidang OP adalah } \\
\text { Melaksanakan operasi } \\
\text { dan pemeliharaan } \\
\text { sumber daya air pada } \\
\text { wilayah sungai. }\end{array}$ & $\begin{array}{l}\text { - Pengelola kegiatan pemeliharaan } \\
\text { Embung Sei Gesek Satker OP BWS } \\
\text { Sumatera IV. } \\
\text { - Kerjasama dengan para pemilik } \\
\text { kepentingan khususnya dalam hal } \\
\text { operasional. } \\
\text { - Keberadaan wadah koordinasi } \\
\text { pengelola SDA. }\end{array}$ & $\begin{array}{l}\text { Meningkatkan kapasitas Satker } \\
\text { OP BWS Sumatera IV dalam } \\
\text { pengelolaan penyediaan air } \\
\text { baku Embung Sei Gesek. }\end{array}$ \\
\hline B & $\begin{array}{l}\text { Pelanggan } \\
\text { Kepentingan) }\end{array}$ & $\begin{array}{l}\text { - Ketersediaan air. } \\
\text { - Kualitas air. } \\
\text { - Kepuasan Pelayanan. } \\
\text { - Komunikasi dan Evaluasi pelayanan } \\
\text { oleh PDAM Tirta Bintan terhadap } \\
\text { pengguna air. }\end{array}$ & $\begin{array}{l}\text { Meningkatkan kepuasan } \\
\text { pelanggan (pemilik kepentingan) } \\
\text { dengan adanya pengelolaan air } \\
\text { baku Embung yang terpadu. }\end{array}$ \\
\hline C & $\begin{array}{l}\text { Pembelajaran } \\
\text { pengembangan }\end{array}$ & $\begin{array}{l}\text { - Pengembangan SDM. } \\
\text { - Pengembangan teknologi. } \\
\text { - Pengembangan sistem pengelolaan } \\
\text { OP. }\end{array}$ & $\begin{array}{l}\text { Meningkatkan } \\
\text { kapasitas/kemampuan SDM } \\
\text { pengelola OP, memanfaatkan } \\
\text { teknologi untuk peningkatan } \\
\text { kinerja penyediaan air baku } \\
\text { embung, dan mengembangkan } \\
\text { sistem penyediaan air baku. }\end{array}$ \\
\hline D & Proses Bisnis Internal & $\begin{array}{l}\text { - } \text { Perencanaan strategis dalam } \\
\text { kegiatan pemeliharaan Embung Sei } \\
\text { Gesek. } \\
\text { - Buku manual teknis pemeliharaan } \\
\text { Embung Sei Gesek. } \\
\text { - Kegiatan pengamanan dan } \\
\text { pencegahan. } \\
\text { - Pelaksanaan pemeliharaan rutin } \\
\text { Embung. } \\
\text { - Pelaksanaan pemeliharaan berkala } \\
\text { - Kembung. } \\
\text { - Kegiatan perbaikan. } \\
\text { - Pengiatan penggantian. } \\
\text { - Pelayanan oleh PDAM. }\end{array}$ & $\begin{array}{l}\text { Untuk efisiensi pemanfaatan air } \\
\text { dan untuk menjaga agar } \\
\text { Embung Sei Gesek berfungsi } \\
\text { sesuai rencana melalui kegiatan } \\
\text { OP. }\end{array}$ \\
\hline$E$ & Keuangan & $\begin{array}{l}\text { - Penyusunan anggaran. } \\
\text { - Efisiensi anggaran. }\end{array}$ & $\begin{array}{l}\text { Untuk efisiensi dan efektifitas } \\
\text { keuangan dalam kegiatan } \\
\text { penyediaan air baku Embung Sei } \\
\text { Gesek. }\end{array}$ \\
\hline
\end{tabular}

Sumber: data diolah penulis 
Pada penelitian ini, kuesioner merupakan alat yang digunakan penulis untuk memperoleh data yang relevan dengan tujuan penelitian ini. Responden yang dipilih merupakan pihak yang mengetahui dan terlibat langsung dalam kegiatan operasi dan pemeliharaan Embung Sei Gesek. Sementara untuk populasi pelanggan, responden ditentukan berdasarkan pembagian lokasi yaitu lokasi yang terdekat dengan sumber air, lokasi yang berada ditengah, dan lokasi yang terjauh dari sumber air dengan jumlah responden masing-masing 10 orang per cluster. Hal ini dilakukan agar diperoleh hasil yang lebih akurat mengenai persepsi pelangganterhadap kinerja penyediaan air baku Embung Sei Gesek. Teknik pegambilan sampel dan data responden dapat dilihat pada tabel 4.

Tabel 4.

Pemetaan Sampel dan Responden

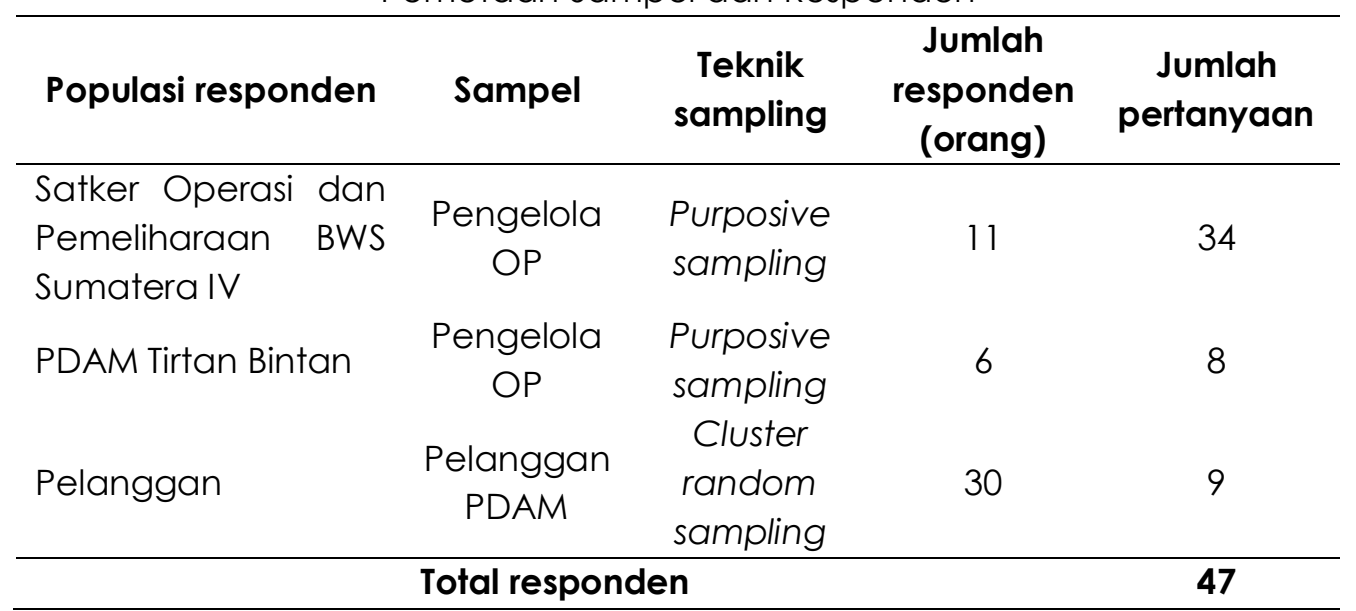

Sumber: Data diolah penulis

\section{HASIL DAN PEMBAHASAN}

\section{Uji Validitas dan Reliabilitas}

Uji validitas dilakukan untuk mengukur valid atau tidaknya suatu kuesioner. Pengujian validitas dalam penelitian ini dilakukan dengan cara mengkorelasikan skor masing-masing pernyataan item dengan total skor untuk seluruh item pernyataan yang ditujukan kepada responden (Muzdalifah, 2013). Pada penelitian ini, uji validitas dan reliabilitas menggunakan software SPSS Statistics 22.

Uji reliabilitas atau Uji reliabilitas merupakan ukuran suatu kestabilan dan konsistensi responden dalam menjawab hal yang berkaitan dengan konstruk pertanyaan yang merupakan dimensi suatu variabel dan disusun dalam suatu bentuk kuisioner (Nugroho, B.A., 2005). Uji ini dilakukan untuk mendapatkan tingkat ketepatan (keandalan atau keajegan) alat pengumpul data (instrumen) yang digunakan (Muzdalifah, 2013).

Tinggi rendahnya reliabilitas secara empiris ditunjukkan oleh suatu angka yang disebut koefisien reliabilitas, yang besarnya berkisar antara 0,00-1,00. Semakin tinggi koefisien reliabilitas semakin mendekati angka 1,00 , dan semakin rendah reliabilitasnya koefisien reliabilitasnya semakin mendekati angka 0 . Untuk mengetahui koefisien korelasi signifikan atau tidak yaitu dengan membandingkankannya dengan $r$ tabel untuk significant $=0,05$, apabila $r 11>r$ tabel berarti reliabel dan sebaliknya bila $r 11<r$ tabel berarti tidak reliabel. Reliabilitas suatu konstruk variabel dikatakan baik jika memiliki nilai Cronbach's Alpha $>$ dari 0,60 (Nugroho, B.A, 2005). 
Wisdawaty Situmorang

Nadjadji Anwar

Theresia Sri Sidharti

Uji Validitas dan Reliabilitas (Responden Pelanggan PDAM)

Hasil uji validitas dan reliabilitas ditampilkan pada tabel 5 .

$\mathrm{n}=30$

$\mathrm{df}=30-2=28$

$a=5 \%$

Tabel 5.

Hasil Uji Validitas dan Reliabilitas

\begin{tabular}{ccccc}
\hline r hitung & $\mathbf{r}$ table & $\begin{array}{c}\text { Validitas } \\
\mathbf{r} \text { hitung }>\mathbf{r} \text { tabel }\end{array}$ & $\begin{array}{c}\text { Cronbach's } \\
\text { Alpha }\end{array}$ & $\begin{array}{c}\text { Reliabilitas } \\
\text { Cronbach's } \mathbf{~}>\mathbf{r} \text { tabel }\end{array}$ \\
\hline 0,586 & 0,361 & Valid & & \\
0,717 & 0,361 & Valid & & \\
0,479 & 0,361 & Valid & & Reliabel \\
0,546 & 0,361 & Valid & 0,733 & \\
0,643 & 0,361 & Valid & & \\
0,589 & 0,361 & Valid & \\
0,387 & 0,361 & Valid & \\
0,608 & 0,361 & Valid & \\
0,517 & 0,361 & Valid & \\
\hline \multicolumn{5}{c}{ Sumber: data diolah penulis }
\end{tabular}

Tabel 5 tersebut menunjukkan item-item tersebut valid dan reliabel. Sehingga kuesioner pada penelitian ini dinyatakan valid dan konsisten (reliable).

Uji Validitas dan Reliabilitas (Responden: Satker Operasi dan Pemeliharaan BWS Sumatera IV) Hasil uji validitas dan reliabilitas untuk responden Pengelola OP Satker Operasi dan Pemeliharaan BWS Sumatera IV ditampilkan pada tabel 6.

$\mathrm{n}=11$

$\mathrm{df}=11-2=9$

$a=10 \%$

Tabel 6 menunjukkan bahwa item-item tersebut valid dan reliabel. Sehingga kuesioner pada penelitian ini dinyatakan valid dan konsisten (reliable).

Uji Validitas dan Reliabilitas (Responden Pengelola OP PDAM Tirta Bintan)

Hasil uji validitas dan reliabilitas ditampilkan pada tabel 7.

$\mathrm{n}=6$

$\mathrm{df}=6-2=4$

$a=10 \%$

Tabel 7 tersebut menunjukkan bahwa item-item tersebut valid dan reliabel. Sehingga kuesioner pada penelitian ini dinyatakan valid dan konsisten (reliable). 
Tabel 6.

Hasil Uji Validitas dan Reliabilitas

\begin{tabular}{|c|c|c|c|c|}
\hline$r$ hitung & $r$ tabel & $\begin{array}{c}\text { Validitas } \\
\text { r hitung }>r \text { tabel }\end{array}$ & $\begin{array}{l}\text { Cronbach's } \\
\text { Alpha }\end{array}$ & $\begin{array}{c}\text { Reliabilitas } \\
\text { Cronbach's } a>r \text { tabel }\end{array}$ \\
\hline 0,662 & 0,5214 & Valid & \multirow{34}{*}{0,961} & \multirow{34}{*}{ Reliabel } \\
\hline 0,602 & 0,5214 & Valid & & \\
\hline 0,662 & 0,5214 & Valid & & \\
\hline 0,626 & 0,5214 & Valid & & \\
\hline 0,695 & 0,5214 & Valid & & \\
\hline 0,662 & 0,5214 & Valid & & \\
\hline 0,531 & 0,5214 & Valid & & \\
\hline 0,712 & 0,5214 & Valid & & \\
\hline 0,662 & 0,5214 & Valid & & \\
\hline 0,873 & 0,5214 & Valid & & \\
\hline 0,711 & 0,5214 & Valid & & \\
\hline 0,522 & 0,5214 & Valid & & \\
\hline 0,725 & 0,5214 & Valid & & \\
\hline 0,575 & 0,5214 & Valid & & \\
\hline 0,670 & 0,5214 & Valid & & \\
\hline 0,670 & 0,5214 & Valid & & \\
\hline 0,695 & 0,5214 & Valid & & \\
\hline 0,695 & 0,5214 & Valid & & \\
\hline 0,583 & 0,5214 & Valid & & \\
\hline 0,754 & 0,5214 & Valid & & \\
\hline 0,803 & 0,5214 & Valid & & \\
\hline 0,609 & 0,5214 & Valid & & \\
\hline 0,762 & 0,5214 & Valid & & \\
\hline 0,611 & 0,5214 & Valid & & \\
\hline 0,695 & 0,5214 & Valid & & \\
\hline 0,663 & 0,5214 & Valid & & \\
\hline 0,721 & 0,5214 & Valid & & \\
\hline 0,646 & 0,5214 & Valid & & \\
\hline 0,749 & 0,5214 & Valid & & \\
\hline 0,561 & 0,5214 & Valid & & \\
\hline 0,626 & 0,5214 & Valid & & \\
\hline 0,687 & 0,5214 & Valid & & \\
\hline 0,685 & 0,5214 & Valid & & \\
\hline 0,559 & 0,5214 & Valid & & \\
\hline
\end{tabular}

Sumber: data diolah penulis 
Wisdawaty Situmorang

Nadjadji Anwar

Theresia Sri Sidharti

Tabel 7.

Hasil Uji Validitas dan Reliabilitas

\begin{tabular}{ccccc}
\hline r hitung & r tabel & $\begin{array}{c}\text { Validitas } \\
\text { r hitung }>\text { r tabel }\end{array}$ & $\begin{array}{c}\text { Cronbach's } \\
\text { Alpha }\end{array}$ & $\begin{array}{c}\text { Reliabilitas } \\
\text { Cronbach's } \mathbf{~}>\mathbf{r} \text { tabel }\end{array}$ \\
\hline 0,749 & 0,729 & Valid & & \\
0,937 & 0,729 & Valid & & \\
0,867 & 0,729 & Valid & & \\
0,811 & 0,729 & Valid & 0,940 & Reliabel \\
0,839 & 0,729 & Valid & & \\
0,937 & 0,729 & Valid & & \\
0,937 & 0,729 & Valid & & \\
0,839 & 0,729 & Valid & & \\
\hline
\end{tabular}

Sumber: data diolah penulis

\section{Rekapitulasi Hasil Evaluasi Kinerja Penyediaan Air Baku Embung Sei Gesek}

Dari pengolahan data kuesioner diperoleh nilai kinerja dari masing-masing BKK untuk Tahun 2018. Nilai kinerja tersebut selanjutnya direkap seperti yang ditampilkan pada tabel 8. Dari tabel 8 maka diperoleh nilai rata-rata evaluasi kinerja penyediaan air baku Embung Sei Gesek sebagai berikut:

$$
\text { Nilai rata2 } \text { kinerja }=\frac{\text { Total Nilai } B S C}{\text { Total Nilai Max }} \times \text { Nilai Max }
$$

$$
\text { Nilai rata2 kinerja }=\frac{216,8}{255} \times 5=\mathbf{4 , 2 5}
$$

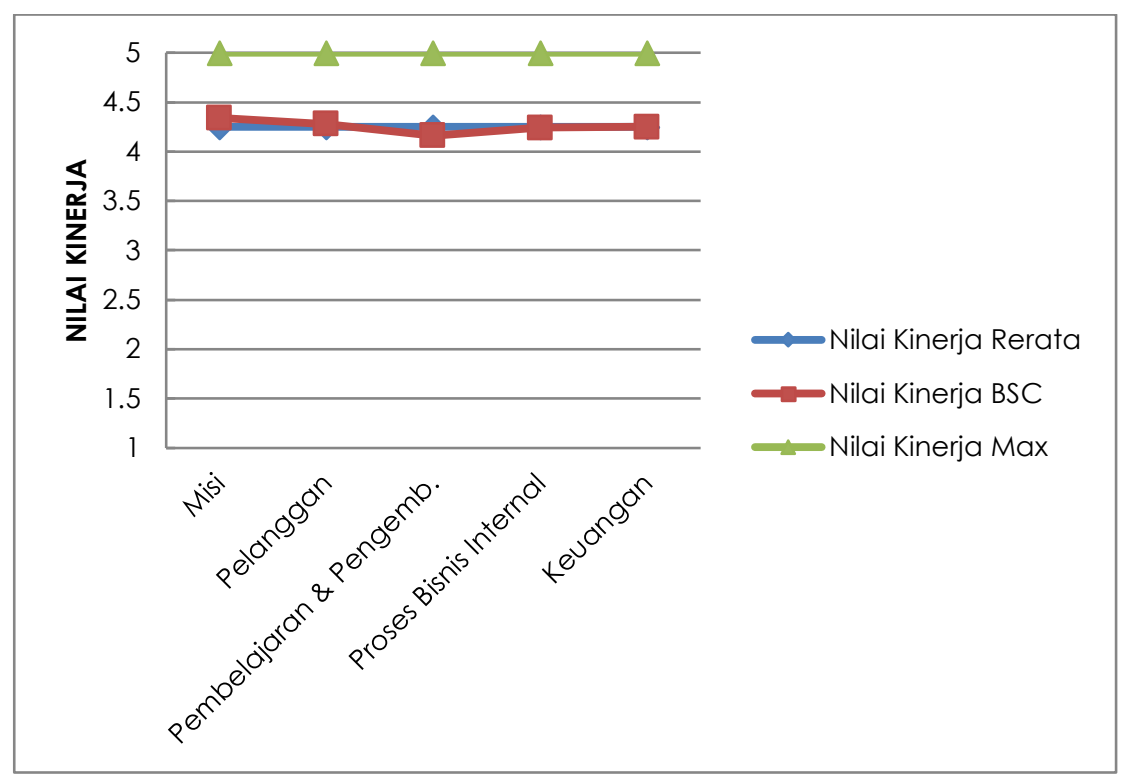

Grafik 1.

Grafik perbandingan nilai kinerja penyediaan air baku Embung Sei Gesek Sumber: data diolah penulis 
Tabel 8.

Hasil Evaluasi Kinerja Penyediaan Air Baku Embung Sei Gesek

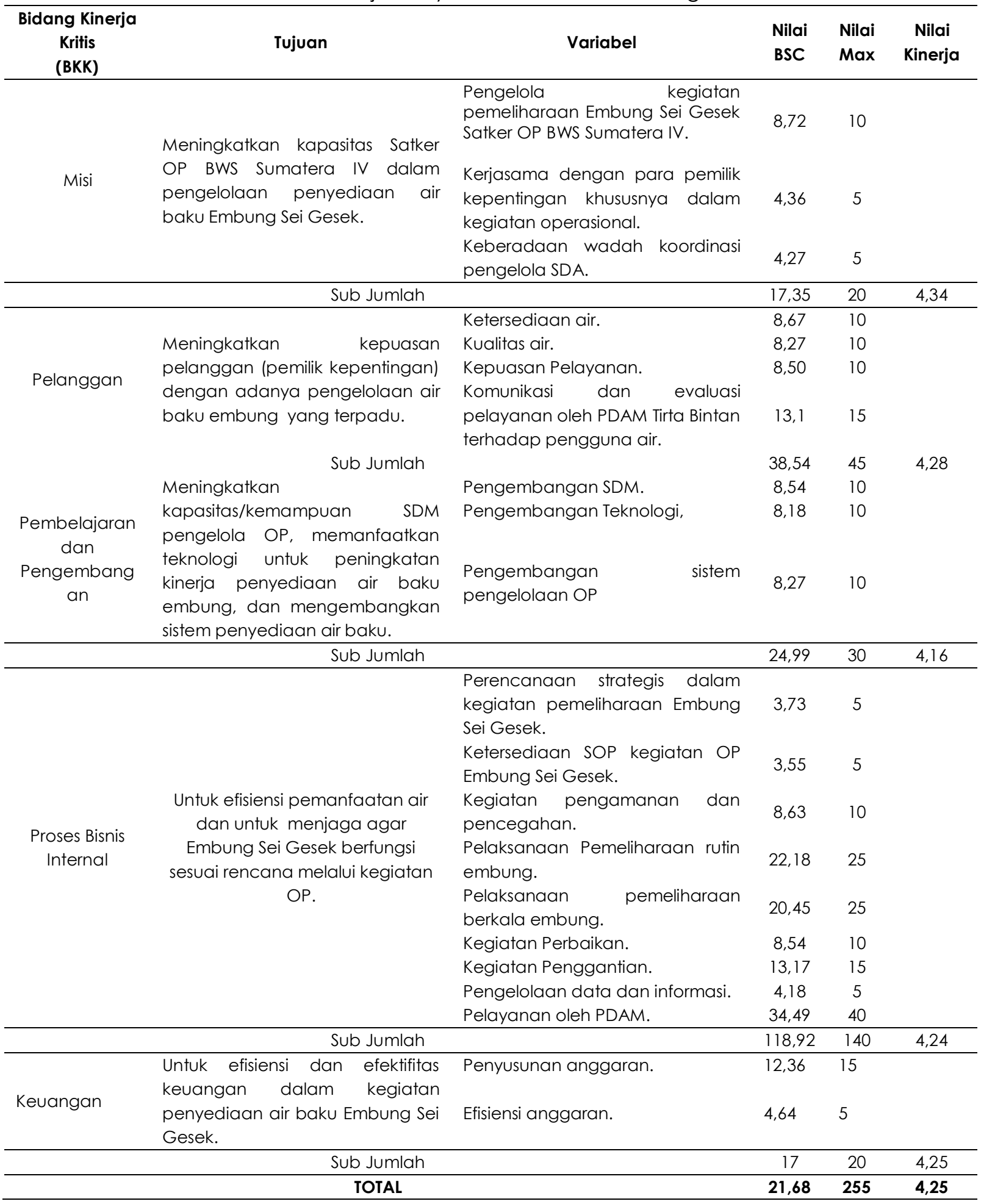

Sumber: data diolah penulis

\section{SIMPULAN}

Pada penelitian ini terdapat lima perspektif (BKK) dan 51 parameter yang digunakan untuk mengevaluasi kinerja penyediaan air baku. Aspek manajemen operasi direpresentasikan oleh BKK Proses Bisnis Internal. Manajemen operasi yang dilakukan meliputi, kegiatan pengamanan dan pencegahan, pelaksanaan pemeliharaan rutin embung, pelaksanaan 


\section{Wisdawaty Situmorang \\ Nadjadji Anwar \\ Theresia Sri Sidharti}

pemeliharaan berkala embung, kegiatan perbaikan, kegiatan penggantian, pengelolaan data dan informasi, dan pelayanan oleh PDAM. Dari hasil analisis dengan pendekatan balanced scorecard diperoleh nilai kinerja untuk tiap BKK, yaitu BKK Misi sebesar 4,34; BKK Pelanggan sebesar 4,28; BKK Pembelajaran dan Pengembangan sebesar 4,16; BKK Proses Bisnis Internal sebesar 4,24; dan BKK Keuangan sebesar 4,25. Nilai rata-rata kinerja untuk penyediaan air baku Embung Sei Gesek sebesar 4,25. Dapat disimpulkan bahwa kinerja penyediaan air baku Embung Sei Gesek dengan pendekatan balanced scorecard dinilai baik. Analisis pada penelitian ini sangat bergantung pada pemahaman dan preferensi responden terhadap pernyataan-pernyataan dalam kuesioner.

Sampai saat ini belum ada pedoman untuk melakukan penilaian kinerja embung sehingga variabel-variabel yang digunakan dalam penelitian ini masih perlu diteliti lebih lanjut. Model penilaian kinerja yang digunakan dalam penelitian ini masih sangat sederhana sehingga masih perlu untuk dikembangkan lagi menjadi model yang lebih baik lagi.Selain itu, indikator/parameter penilaian kinerja yang digunakan juga masih terbatas sehingga masih perlu dikaji lagi faktor-faktor lain yang mungkin dapat mempengaruhi kinerja.

\section{DAFTAR PUSTAKA}

Antono. 2013. Balanced Scorecard-Primadona dalam Basis Pengukuran Kinerja menuju Reformasi Birokrasi. Buletin Pengawasan 92: 10-13.

Balai Wilayah Sungai Sumatera IV. 2018. Laporan Akhir Angka Kebutuhan Nyata Operasi dan Pemeliharaan (AKNOP). Batam: BWS Sumatera IV

Balai Wilayah Sungai Sumatera IV. 2015. SID Penyediaan Air Baku Sungai Gesek. Batam: BWS Sumatera IV

Bunganaen, Wilhelmus. 2013. Analisis Kinerja Embung Oelomin di Kabupaten Kupang. Jurnal Teknik Sipil (2/1): 23-36

Direktorat Jenderal Sumber Daya Air. 2015. Pedoman Pengukuran Kinerja Organisasi Pengelola Sumber Daya Air Wilayah Sungai (RBO Performance Benchmarking). Jakarta: Ditjen SDA.

Gaspersz, V. 2006. Sistem Manajemen Kinerja Terintegrasi Balanced scorecard dengan Six Sigma untuk Organisasi Bisnis dan Pemerintah. Jakarta: PT. Gramedia Pustaka Utama.

Isnugroho. 2013. Pengukuran Kinerja Organisasi Pengelola Wilayah Sungai dengan Menggunakan Balanced Scorecard. Jurnal Sumber Daya Air (9/2): 143-154.

Muhtadi. 2009. Manajemen Pemeliharaan untuk Optimalisasi Laba Perusahaan. Jurnal Pendidikan Akuntansi Indonesia (9/1): 35-43.

Muzdalifah, L. 2013. Optimalisasi Operasi dan Pemeliharaan Irigasi Melalui Penguatan Kelembagaan Pengelola Irigasi Studi Kasus Daerah Irigasi Barugbug Provinsi Jawa Barat. Tesis.Bandung: Program Pasca Sarjana Jurusan Teknik Sipil Institut Teknologi Bandung. 
Nugroho, B.A. 2005. Strategi jitu memilih metode statistik Penelitian dengan SPSS. Yogyakarta: Penerbit Abdi.

Sugiyono. 2010. Metode Penelitian Pendidikan. Bandung: Alfabeta

Widiyarto, A. E. 2017. Evaluasi Kinerja Operasi dan Pemeliharaan Bendungan Cengklik dengan Menggunakan Balanced scorecard. Tesis Surakarta: Program Pasca Sarjana Jurusan Teknik Sipil Universitas Muhammadiyah Surakarta. 